\title{
A POTÊNCIA LITERÁRIA E EPISTEMOLÓGICA DO PROVÉRBIO: UM NOVO LOCAL DE ENUNCIAÇÃO
}

"Até que os leões tenham as suas histórias, os contos de caça glorificarão sempre o caçador." (Provérbio africano)

Resumo: A proposta deste ensaio é refletir acerca da potência epistemológica e literária do provérbio, pensando a partir das teorias de Boaventura Sousa Santos, Édouard Glissant e Walter Mignolo. A presença de provérbios - expressão ou frase curta facilmente memorável, expressão de algo tido como verdadeiro a partir das observações práticas da vida - é uma constante, sobretudo em textos de escritores africanos, como um efetivo marco daquela cosmovisão que valora sobremaneira a sabedoria dos antigos, seja no início da obra literária como chaves de leituras que vão preparar "o campo" para a narrativa subsequente, dando-lhe forte profundidade e significação. É notório, porém, perceber como esse gênero literário foi (e ainda é) apequenado pela tradição literária, cujo potencial epistemológico é deliberadamente recalcado, esquecido de nossas vistas, ainda que seja parte integrante e fundamental da narrativa.

Palavras-chave: Provérbio; Literatura africana; Boaventura Sousa Santos; Édouard Glissant; Walter Mignolo.

Abstract: The proposal of this essay is to reflect on the epistemological and literary power of the proverb, rising from the theories of Boaventura Sousa Santos, Édouard Glissant and Walter Mignolo. The presence of proverbs - expression or easily memorable phrase, expression of something taken as true from the practical observations of life - is a constant, especially on texts by African writers, as an effective Marco for that cosmoview which greatly valorizes the wisdom of the ancients, to be in the beginning of the literary work like keys to readings that will prepare "the field" for a subsequent narrative, making it have depth and meaning. It is, however, notorious realizing how this literary genre has been smalled by the literary tradition, which epistemological power is deliberately repressed, gone from our sight, even though it is an important and fundamental member of narrative.

Keywords: Proverb; African literature; Boaventura Sousa Santos; Édouard Glissant; Walter Mignolo. 


\section{INTRODUÇÃO}

Boaventura Sousa Santos (2006), ao propor uma "ecologia dos saberes", sugere que esta seja configurada dentro de uma constelação ampla e plural de saberes heterogêneos coexistentes, considerando-os autônomos e horizontais entre si. Esse conceito possui significativa conexão com o pensamento de Glissant (1990), metaforizado pela "poética da relação", cuja proposta pode-se facilmente estabelecer links ao de Boaventura Santos, no que tange à horizontalidade das multiplicidades das expressões culturais dos povos, sem a menor possibilidade de hierarquização, pensando-se que nas imensas possibilidades e relações há certa sincronicidade no dinamismo do caos.

Partindo do mesmo pressuposto dos pensadores supracitados, no que se refere aos desafios de superar os processos de hierarquização e subalternização fundamentados pela colonialidade do poder, Mignolo (2003) pontua a emergência de novos locais de enunciação, o que ele vai alcunhar de "pensamento liminar", em que a epistemologia subalternizada historicamente resiste para afirmar os seus saberes, em luta para lograr seu espaço de poder. Em conformidade com esse autor, este é um período fecundo para emergência de um "outro pensamento" cujo 
intuito é apontar para uma razão pós-ocidental. Mignolo (2003), assim como Glissant (1990) e Boaventura Santos (2006), cada um ao seu estilo e local de fala, percebem que a potência epistemológica só abrange e emerge de certos locais geopolíticos, demonstrando como o imaginário sempre esteve marcado pelo sistema moderno/colonial, em que uma colonização epistemológica calcada no etnocentrismo foi/é uma constante.

\section{PROVÉRBIOS, FRASES PRONTAS, DITOS POPULARES COMO POTÊNCIAS LITERÁRIAS E EPISTEMOLÓGICAS}

Esse preâmbulo acerca da emergência desse novo lugar de enunciação e da visão rizomática e coexistente das epistemes, de que falam Glissant, Mignolo e Santos, é o ensejo necessário para tratar de uma potência literária ainda hoje marginalizada nos espaços de poder e "erudição", tida como um saber 'menor': a oratura do provérbio.

A presença de provérbios - expressão ou frase curta facilmente memorável, expressão de algo tido como verdadeiro a partir das observações práticas da vida - é uma constante, sobretudo em textos de escritores africanos, como um efetivo marco daquela cosmovisão que valora sobremaneira a sabedoria dos antigos, seja no início da obra literária e/ou como chaves de leituras que vão preparar 
o campo para a narrativa subsequente, dando-lhe forte profundidade e significação.

É notório, porém, perceber como esse gênero literário foi (e ainda é) apequenado pela tradição literária, cujo potencial epistemológico é deliberadamente recalcado, esquecido de nossas vistas, ainda que seja parte integrante e fundamental da narrativa. Por vezes, até aqueles que estudam as literaturas orais africanas esquecem-se de destacar em suas análises a semântica deste texto e sua forte significação nas narrativas, em que a ancestralidade se dá pela via da marcação oral do provérbio, que é reinventada de forma rasurada pela escrita, cujas letras e sons coexistem. As marcações de frases prontas, mitos e provérbios evocam o espaço do contador de estórias na narrativa, em que a performance dos sons está presente, ainda que na escrita e no papel.

Considero que quando Boaventura Sousa Santos (2006), propondo uma ecologia dos saberes, apoia-se "na independência complexa entre os diferentes saberes que constituem o sistema aberto do conhecimento em processo constante de criação e renovação; em que o conhecimento é interconhecimento, reconhecimento e autoconhecimento" (p.157), ele evoca os saberes silenciados - tidos como culturais, folclóricos em vez de epistemológicos - como 
potências, e a sabedoria proverbial é uma delas. Walter Mignolo (2003), por sua vez, na mesma linha da proposta de Santos, em seu conceito de "pensamento liminar", sugere que este "outro pensamento"

tem a possibilidade de superar a limitação do pensamento territorial (isto é, a epistemologia monotópica da modernidade), cuja vitória foi possibilitada por seu poder de subalternizar o conhecimento localizado fora dos parâmetros das concepções modernas de razão e racionalidade. Uma dupla crítica libera conhecimentos que foram subalternizados, e a liberação desses conhecimentos possibilita "um outro pensamento". (MIGNOLO, 2003, p.103)

Édouard Glissant (1990), por seu turno, em seu conceito de "pensamento arquipélago" recorda-nos tanto o conceito de ecologia dos saberes de Santos (2006), quanto o conceito de "pensamento liminar" de Mignolo (2003), sugerindo uma convivência entre as culturas sem deixar que se perca a profusão das singularidades e sem olhá-las sob óticas hierarquizantes.

Percebendo os provérbios numa categorização ainda inexplorada pelos estudos literários e vendo neles uma potência comunicativa e epistemológica, o professor baiano Henrique Freitas (2016) afirma que 
os provérbios evocam uma sabedoriasíntese rasurante ao próprio campo dos estudos literários. [...] Essa gnose multissemiótica que perpassa os provérbios [...] não é armazenada estaticamente em arquivos materiais escritos, mas revivido, reatualizado e ritualizado no devir grupal, vez que é uma sabedoria provinda de iniciações. (FREITAS, 2016, p.74-75)

Filósofos africanos como o moçambicano José Castiano (2014) percebem na oratura sistemas profundos de pensamentos que podem ser equiparados aos sistemas filosóficos ocidentais. Provérbios, mitos, contos, ditos populares, adivinhas e outras formas de oraturas seriam axiomas que "pretendem interpretar ou prescrever o comportamento e os princípios da ação dos habitantes da comunidade ou sociedade [...]." (CASTIANO, 2014, p.41).

Castiano (2014), assim como diversos filósofos de formação africana, insiste em mostrar como outros saberes, inclusive os iletrados, podem ser lidos como filosóficos. Os seus intentos são mostrar que os meios tradicionais perfazem a filosofia e nesse sentido, eles buscam fundamentar "uma filosofia africana a partir das manifestações e espaços tradicionais da entrega desinteressada ao saber" (CASTIANO, 2014, p.42). 0 filósofo moçambicano vai propor uma categoria de filosofia africana chamada "sagacidade filosófica": 
A categoria filosófica diz respeito àqueles sages preocupados pelos problemas éticos e empíricos fundamentais, que sejam relevantes para a continuidade da respectiva comunidade e que, por via disto, demonstrem capacidade de oferecer soluções alternativas aos problemas fundamentais dela mesma. Portanto, preocupações éticas estão no substrato da sagacidade filosófica, segundo a concepção orukiana [e eu acrescento as preocupações didácticometodológicas]. [...] Colocar as questões éticas no centro das preocupações profundas de um sage é o mesmo que dizer que o homem, ou melhor, as condições existenciais são o objecto primordial das suas lucubrações. Os provérbios e o resto seriam axiomas que pretendem interpretar ou prescrever, em primeira linha, o comportamento e os princípios da ação dos habitantes da comunidade ou sociedade em que vive o sage. (CASTIANO, 2014, p.43)

Na obra Filosofia africana: da sagacidade à intersubjetivação, o filósofo busca uma "ética africana ancestral" a partir do que ele chama entre-vistas com o sage filosófico Antonio Viegas cujo pensamento crítico é perceptível em todas as respostas, às quais os saberes locais e endógenos da cultura de base makuwa são subsídios para se pensar o nacional e o universal, isto é, pensar "o universalismo a partir de um ponto onde ele tenha os seus pés bem firmes". 
Mesmo quando introduzia piada em seus discursos, estas encaixavam que nem uma luva no tema em causa. Em numerosas ocasiões nos sentimos desconcentrados pela simplicidade com que ele esmiuçava assuntos completos e delicados de nossa vida, usando como pretexto de aproximação ao temo o ângulo da cultura makuwa. O seu método era usar a cultura de base makuwa para se dirigir ao nacional e ao universal. [...] A cultura makuwa era para ele o ponto de saída seguro para afirmar-se na moçambicanidade e na africanidade. (CASTIANO, 2014, p.21)

Como aponta Mignolo (2003), é preciso pensar na tradição não como significante de algo "anterior" à modernidade, mas algo que subsiste na memória, permanecendo viva. Nesse sentido, há tradições africanas como europeias, e em ambas há "modernidades" e "colonialidades", apesar das disparidades de configurações. Mignolo sugere, nesse ensejo, que é chegada a hora da "Filosofia" ser "apropriada como uma palavra e uma atividade a partir da África ou da América Latina", desse modo, questionar-se a forma arbitrária como esses projetos locais europeus se tornaram projetos globais.

Essa proposta "universo local" sugerida pelo sábio africano Viegas, e que o filósofo Castiano pretende resgatar, remetenos ao conceito de Mignolo (2003, p.99) de "histórias locais do pensamento limiar", que denuncia a formação do sistema 
moderno/colonial cujo primeiro plano é a colonialidade do poder, mas que aponta para uma descolonização epistêmica fundamentada em novos loci de enunciação, que tem como ponto de partida os saberes subalternizados em confronto com as formas de saberes hegemônicos, emergindo, assim, uma nova epistemologia, que redefinirá a geopolítica do conhecimento, descentrando-a do eurocentrismo. Desse modo, pensar o universal sem as amarras sempre hegemônicas do ocidentalismo é, sim, uma manifestação do pensamento limiar cujos saberes, histórias locais/regionais são um passo decisivo para a descolonização intelectual.

A expressão "condições históricas e locais" indica também tanto as histórias locais "dentro" do sistema mundial moderno (por exemplo, as histórias locais dos "centros metropolitanos", as histórias locais da Espanha e da Inglaterra) quanto as histórias locais de suas fronteiras/margens (por exemplo, os Andes sob domínio colonial, a independências dos países latinoamericanos [...]). [...] Os projetos globais, em outras palavras, são fermentados, por assim dizer, nas histórias locais dos países metropolitanos; são implementados, exportados e encenados de maneira diferente em locais particulares (por exemplo, na França e Martinica no século 19). (MIGNOLO, 2003, p.99) 
O agenciamento do provérbio em um texto literário possibilita o que Glissant denomina de raiz-rizoma, na qual não há uma identidade de raiz única, mas uma relação de culturas locais com outras raízes culturais, relacionando-se com elas. Isto é, os elementos da tradição são evocados, mas ultrapassados, sendo reinventados, inter-relacionandose por aquilo que os afetou em sua relação com o Todo-omundo (GLISSANT, 1990, p.100). Nesse sentido, conforme Laura Padilha:

Nelas [em narrativas das vozes privilegiadas de Mia Couto e Pepetela] buscarei algumas recorrências temáticas e/ou discursivas, como por exemplo o entrelace da voz e da letra, a ampliação do campo linguístico do português e a intenção pedagógica ou iniciática a que se acopla um acirramento do plano crítico e contestatório do narrado. Tais traços, dentre outros igualmente elencáveis, já estavam presentes nas malhas ficcionais africanas quando se acirrou o anseio de descolonização e permanecem depois que se entoam as melodias das independências, só que, algumas vezes, em jogo de inversões ou distanciamentos. (PADILHA, 2002, p.39)

O recurso linguístico e sonoro do provérbio como parte da cultura acústica também muda a forma como a mente opera, diferenciando-se da lógica ocidental e rasurando-a, 
e recorrendo aos artifícios da memória, da sonoridade, da redundância, das frases feitas, fórmulas, retóricas de lugarescomuns, etc.

A utilização do provérbio como chave de leitura é, sem dúvida, uma potência epistemológica, sobretudo no universo africano como também no afro-diaspórico. O universo da oratura é, nesse sentido, um espaço fecundo de trânsitos, migrações e traduções, dialogando, ainda que com tensões, a modernidade com o saber ancestral.

O escritor africano, então, agenciaria os modos de construção e expressão característicos da oratura para a construção do texto literário. O termo oratura aponta para o diálogo, nem sempre harmônico, entre formas expressivas ligadas à tradição oral e à escrita. Engloba oratura a simultaneidade: oralidade e escrita, vazada em duplo movimento. A literatura transita entre esses códigos tensionando-os. (FONSECA; CURY, 2008, p.63)

Utilizar a cosmovisão africana, sua acústica, suas marcas ancestrais, suas performances culturais na tessitura do texto em língua portuguesa, inseri-la em um contexto desconstrutor e novo, reapropriando-a, faz parte dessa nova "gnose do pensamento" (MIGNOLO, 2003), em que o sistema mundial colonial/moderno ganha novas configurações e sentidos. 
De maneira geral, as culturas africanas são predominantemente acústicas, não lineares, mas esféricas, circulares, podendo ser vistas como "um outro pensamento" à concepção linear do desenvolvimento histórico ocidental proposta por Hegel, uma vez que, conforme Mignolo, confronta as histórias locais e suas particulares relações de poder, subvertendo as hierarquias; tal circularidade, para estender ainda mais nossos horizontes, pode ser lida como o Paradigma Exu proposto pelo filósofo baiano Eduardo de Oliveira (2007).

A utilização de provérbios, frases prontas, ditos populares, etc. são marcas típicas, por exemplo, da literatura do escritor moçambicano Mia Couto, que, conforme conta o próprio autor, são ditos por ele escutados dentro daquela comunidade e (re) contados à sua emoção e criatividade nas estórias.

O registro escrito do provérbio é constantemente trazido à tona ora como epígrafe pré-narrativa, ora nas falas dos vários personagens miacoutianos que entram e saem da narrativa para nos legar seus saberes, como se verá em alguns contos, como em "Chuva: a abensonhada":

- Mas, Tia Tristereza: não será está chover de mais? De mais? Não, a chuva não esqueceu os modos de tombar, diz a 
velha. E me explica: $A$ água sabe quantos grãos tem a areia. Para cada grão ela faz uma gota." [...] Mas dentro de mim persiste uma desconfiança: esta chuva, minha tia, não será prolongadamente demasiada? Não será que à calamidade do estio se seguirá a punição das cheias? [...] Tristereza olha a encharcada paisagem e me mostra outros entendimentos meteorológicos que minha sabedoria não pode tocar. Um pano sempre se reconhece pelo avesso, ela costuma me dizer. [...] A chuva está a limpar a areia. Os falecidos vão ficar satisfeitos. Agora, era bom respeito o senhor usar este fato. Para condizer com a festa de Moçambique... (COUTO, 2012, p.45 grifo meu)

Como aponta Laura Padilha (2002) em seu ensaio $A$ semântica da diferença, "no tapete criado pelos fios das epígrafes" (2002, p.39) emerge a sabedoria filosoficamente africana, "mordendo o rabo" da greco-romana ocidental, inserindo-nos numa outra lógica de narrativa na qual a tradição se reinventa, ainda que mantendo seus alicerces simbólicos, cuja égide é o espaço cultural africano. No trecho abaixo citado, do livro Terra Sonâmbula, os aspectos simbólicos da tradição e da oralidade aparecem com uma roupagem aliada e híbrida da modernidade: a fogueira, a estória, o menino, o velho, o livro, a voz e a letra imiscuemse nesse entre-lugar: 
- Então vai acender uma fogueira lá fora. O miúdo se levanta [...]. Depois se senta ao lado da fogueira, ajeita os cadernos e começa a ler [...].

- Que estás a fazer rapaz?

- Estou a ler.

- É verdade, já esquecia. Você era capaz ler. Então leia em voz alta que é para me adormecer.

O miúdo lê em voz alta. Seus olhos se abrem mais que a voz que, lenta e cuidadosa, vai decifrando as letras. (COUTO, 1995, p.55)

A presença de provérbios, crenças, ditos, frases prontas, aforismo populares e/ou outros elementos que remetem a uma tradição oral precedendo o texto narrativo contemplam a voz do contador de estórias imiscuída à figura do narrador, dando-Ihe primeira evidência. Essa estratégia textual é uma marca de grande significação na estória, é uma chave de leitura de fundamental relevância que não pode ser vista somente como anexo estético no contexto da narrativa.

Na obra Oúltimo voo doflamingo de Mia Couto, por exemplo, todos os capítulos são introduzidos por provérbios, ditos e crenças locais, palavras prontas dos mais velhos, depoimentos axiomáticos do feiticeiro local, etc. que convidam o leitor a adentrar no capítulo seja pelo desafio do enigma que alguns se configuram, pela curiosidade, pela sugestão simbólica, ou pelo riso que os pequenos fragmentos evocam. 
Já nos contos "Nas águas do tempo" e "Chuva: a abensonhada", os provérbios, ditos e aforismos populares aparecem não nas epígrafes das narrativas propriamente, mas são construídos enriquecendo e endossando os diálogos ao longo de toda a estória, que vai sendo "desvendada" através das falas marcadamente simbólicas dos velhos contadores, que costumam ser mais contadores do que os narradores que conduzem o enredo:

Sempre em favor da água, nunca esqueça! Era sua advertência. Tirar água no sentido contrário ao da corrente pode trazer desgraça. Não se pode contrariar os espíritos que fluem. Depois viajávamos até ao grande lago onde nosso pequeno rio desaguava. Aquele era o lugar das interditas criaturas. [...] Nessa noite, ele me explicou suas escondidas razões. Meus ouvidos se arregalavam para lhe decifrar a voz rouca. Nem tudo entendi. No mais ou menos, ele falou assim: nós temos olhos que se abrem, para dentro, esse que usamos para ver os sonhos. $\mathrm{O}$ que acontece, meu filho, é que quase todos estão cegos, deixaram de ver esses outros que nos visitam. Os outros? Sim, esses que nos acenam da outra margem. E assim Ihes causamos uma tristeza. Eu levo-Ihe lá nos pântanos para que você aprenda a ver. Não posso ser o último a ser visitado pelos panos. (COUTO, 2012, p.10-13 - grifo meu) 
Maria Nazareth Fonseca e Maria Zilda Cury (2008, p.68) sinalizam ainda que o escritor moçambicano Mia Couto, em suas narrativas, faz um processo de apropriação dos provérbios, em que costuma inverter o caráter conservador e cristalizado típico das máximas, dando-as uma nova leitura, ampliando a possibilidade de significação: “Agora o surpreendia preparado para o que desse e não viesse" (COUTO, 2003, p.60); “Eu queria amolecer a pedra, mas não havia água que chegasse" (COUTO, 2003, p.168); ou ainda em "De grão em grão o papa se enche de galinhas" (COUTO, 1995, p.129). Isso é feito também para fugir do lugar-comum, explorar os sentidos da linguagem e/ou ainda fomentar uma maior poeticidade nos provérbios, como ocorrem nas releituras de "devagar se vai longe" para "a lua vai devagar mas atravessa o mundo" (COUTO, 2003, p.175), como também em "No charco onde a noite se espelha, o sapo acredita voar entre estrelas" (COUTO, 2003, p.118), cujo desejo pelo poético também se faz notório no provérbio.

Apesar do grande rol de configurações em que se apresenta esse gênero no texto literário, ainda se identifica nos estudos literários o espaço de deslegitimação dado ao provérbio, isso é muito claro quando o comparamos a outro gênero de formato parecido: o haicai. O espaço dado ao 
haicai na literatura é efetivo e legítimo, muitos escritores brasileiros, por exemplo, utilizaram-se desse gênero para "escrever literatura", vide Paulo Leminski, Mário Quintana, Millôr Fernandes, só para citar alguns exemplos mais canônicos.

No caso do Brasil, temos um grande nome na literatura que tem sua égide literária na produção de cânticos e provérbios através da sabedoria filosófica angariada no Candomblé, a lalorixá e acadêmica baiana Mãe Stella de Oxóssi. Com seis livros publicados, ocupa a Academia baiana de Letras, nada obstante, percebamos que muitas vezes sua literatura sequer é citada e valorada como literatura, e o potencial epistemológico de sua produção malbaratado em face de utilizar-se de gêneros típicos da oralidade.

Quando a escritora Mãe Stella de Oxóssi assumiu a cadeira 33, cujo patrono foi ninguém mais que Castro Alves, algumas veiculações midiáticas da internet ainda citaram duas de suas obras, alguns jornais audiovisuais sequer citaram uma publicação literária da lalorixá e não evocaram sua faceta escritora e/ou acadêmica, retratando-a apenas de mãe-desanto ou ialorixá. Detendo-se rapidamente, essa discussão pode parecer diminuta, uma vez que o principal é que uma "mãe-de-santo" superou as muralhas quadrangulares do 
cânone e dos preconceitos e consagrou-se partícipe da Academia de Letras da Bahia, entretanto, a deslegitimação desenha-se de outras formas, com outros sabores e configurações.

Destarte, muito coadunando com a raiz dos conceitos dos teóricos supracitados, cujas ideias, em súmula, sugerem respeitar a individualidade de cada saber sem subalternizalo e diminuí-lo pela hierarquização, a própria escritora e colunista Mãe Stella de Oxossi sugere, neste ensejo ${ }^{1}$, o seguinte:

Foi através da tradição oral, chamada na língua yorubá de ipitan, que entrei em contato com a maravilhosa arte de viver do africano, que tem na alegria um de seus fundamentos. Entretanto, nós brasileiros, que temos nesse povo uma de nossas descendências, não devemos correr o risco de sermos megalomaníacos e considerar a filosofia africana a melhor. Todo povo possui sua sabedoria, mas a Sabedoria, assim como Deus, é uma só. A mesma base, os mesmo fundamentos, apenas transmitidos de acordo com a cultura e o lugar de viver correspondente. Se foi através da tradição oral que aprendi, é agora na escrita, iwe-kikó, que encontro condições favoráveis para transmitir, a um maior número de pessoas, os ensinamentos

1 Artigo publicado na coluna Opinião do Jornal Atarde, de Salvador, no dia 25 de maio de 2011, dia em que se dedica à África. 
absorvidos e os quais ainda pretendo assimilar, de maneira profunda. (SANTOS, 2011 - grifo meu)

\section{PRETENDENDO ALGUMAS CONSIDERAÇÕES FINAIS...}

Em uma das ecologias dos saberes proposta por Boaventura Sousa Santos (2006), há um marcante combate contra as hierarquias e poderes universais que foram naturalizados pela história e por epistemologias reducionistas, assim como em Édouard Glissant (1990) são evocadas as fraturas, contradições que nos apontam para o caos e rasuram a metafísica ocidental tida pela história como episteme inquebrantável, fixa e mecânica.

A "história oficial" promoveu durante muito tempo apagamentos, silenciamentos, recalcamentos que ora são "profetizados" por contradiscursos que vão rasurar e recontar as histórias, sob novos prismas; essa é também uma das propostas da poética da relação de Glissant.

A descolonização epistemológica pautada no eurocentrismo emerge quando propomos reflexões como as deste ensaio, pois que suscitam os "novos loci de enunciação", a que Mignolo (2003) tanto se referiu em sua obra, em que saberes subalternizados confrontam os hegemonizados, propondo, assim, novas epistemologias que interagem a 
partir e entre as várias histórias locais, rearticulando, dessa forma, a geopolítica do conhecimento.

O trabalho intelectual do filósofo Castiano (2014), assim como de Mbembe (2014), Ramose (2010), entre outros estudiosos do gênero provérbio, também são partícipes desse contradiscurso, evocando saberes subalternizados para um novo local de análise e pesquisa que perpassam o mero reducionismo do senso comum, do exótico, folclórico ou cultural, para soerguer o potencial epistemológico que subjaz nesses saberes, que precisam ser explorados.

\section{REFERÊNCIAS}

CASTIANO, José (2014). Filosofia Africana: da Sagacidade à intersubjectivação com Viegas. Moçambique: Editora Educar.

COUTO, Mia (1995). Terra sonâmbula. Rio de Janeiro: Nova Fronteira. (2005). O último voo do flamingo. São Paulo: Cia das Letras. (2012). “Nas águas do tempo". In: Estórias abensonhadas. São Paulo: Companhia das Letras.

(2012). "Chuva: a abensonhada". In: Estórias abensonhadas. São Paulo: Companhia das Letras. (2003). Um rio chamado tempo, uma casa chamada terra. São Paulo: Companhia das Letras.

FONSECA, Maria Nazareth Soares; CURY, Maria Zilda Ferreira (2008). Mia Couto: espaços ficcionais. Belo Horizonte: Autêntica.

FREITAS, Henrique (2016). O arco e a arkhé: ensaios sobre literatura e cultura. Salvador: Editora Ogum's Toques Negros. GLISSÁNT, Édouard (1990). Poética da relação. Paris: Éditions Du Seuil. 
MBEMBE, Achille (2014). Crítica da razão negra. Lisboa: Antígona editores. MIGNOLO, Walter (2003). Histórias locais, projetos globais. Belo Horizonte: Editora da UFMG.

OLIVEIRA, Eduardo (2007). Filosofia da Ancestralidade: corpo e mito na filosofia da educação brasileira. Curitiba: Gráfica e Editora Popular.

PADILHA, Laura Cavalcante (2002). Novos pactos, outras ficções: ensaio sobre literaturas afro-luso-brasileiras. Porto Alegre: EDIPUCRS.

SANTOS, Boaventura Sousa (2006). A gramática do tempo: para uma nova cultura política. São Paulo: Cortez.

Lívia Maria Costa Sousa é Graduada em Letras Vernáculas pela Universidade do Estado da Bahia (2014), Campus I, Salvador. Bolsista de Iniciação Científica primeiramente pelo PICIN (UNEB) e em seguida pela FAPESB, realizando pesquisas acerca da Literatura Comparada, Literatura Africana de Língua Portuguesa e Estudos Culturais. Atualmente é Mestranda em Literatura e Cultura na Universidade Federal da Bahia (2015), além de ser graduanda em Filosofia também pela Universidade Federal da Bahia. Leciona Língua portuguesa e literaturas, trabalha com edição e revisão de livros. 